Review Article

\title{
Di-2-ethylhexylphthalate May Be a Natural Product, Rather than a Pollutant
}

\author{
Aurelio Ortiz and Estibaliz Sansinenea \\ Facultad de Ciencias Químicas, Benemérita Universidad Autónoma de Puebla, C.P. 72570, Puebla, PUE, Mexico \\ Correspondence should be addressed to Estibaliz Sansinenea; estisansi@yahoo.com.mx
}

Received 28 June 2018; Revised 22 August 2018; Accepted 3 September 2018; Published 26 September 2018

Academic Editor: Qizhen Du

Copyright (C) 2018 Aurelio Ortiz and Estibaliz Sansinenea. This is an open access article distributed under the Creative Commons Attribution License, which permits unrestricted use, distribution, and reproduction in any medium, provided the original work is properly cited.

Di-2-ethylhexylphtalate is an ester of phthalic acid that has been used as plasticizer in many materials. Due to the extended use, it has been persistently found in different environments being classified as a pollutant with some risks for human health. However, in the last years, it has been found that this compound is produced by plants or microorganisms like bacteria or fungi. This finding opened a serious debate about the origin of this compound and questioned if it is a real pollutant or a natural metabolite with some biological activities that could help us in several ways. This review tries to give some data of the different points of view about this question.

\section{Introduction}

Phthalate compounds are colorless liquid chemicals that have been used as plasticizers to improve the plasticity and the flexibility of materials such as food packages, building, toys, medical devices such as blood storage bags, intravenous fluid bags, and other products $[1,2]$. Di-2-ethylhexylphtalate (DEHP) has been persistently found in different terrestrial and aquatic environments resulting in one of the most important pollutants in the world [3]. These compounds are released from industrial products, and their photodegradation are very slow under natural conditions. Therefore, measurable concentrations of phthalate compounds accumulate over time in environments such as air, soil, water, and sediments causing a high human exposure [4]. The human beings can accumulate this compound through inhalation, skin contact, and the food chain. In this sense, many studies have been carried out regarding the toxicity effects of this compound in human health. These compounds are suspected to cause teratogenicity, mutagenicity, and carcinogenicity even at very low concentrations [5]. Increased awareness of phthalates toxicity has led to a dramatic increase in concern about the fate and removal of these pollutants in and from the environment. To reduce the presence of these compounds in the environment, many reactions have been reported to degrade and transform these compounds. One of the most effective methods is employing a great variety of microorganisms to biodegrade pollutants because it is simple, cheaper, and environmentally friendly. Several strains belonging to the genera Sphingomonas, Pseudomonas, Rhodococcus, Agromyces, Acinetobacter, Microbacterium, and Gordonia have been reported as DEHP-degrading bacteria [6-10]. These bacteria have been isolated from natural environments such as soil, water, or sediments; therefore, their use as biodegrading bacteria is environmentally friendly since they have natural source, form part of natural chain, and use natural metabolic pathways both under anaerobic and aerobic degradation, converting DEHP in less harmful metabolic secondary compounds [2]. In the same way, a series of phthalatedegrading fungal species has been summarized in previous studies [11] such as, Aspergillus parasiticus, Fusarium subglutinans, and Penicillium funiculosum, which can completely consume intact DEHP, either singly or in groups [12]. However, there is another part in this story that can generate controversy about the origin of this compound. This compound has been isolated from many microorganisms such as bacteria and fungi. The natural biosynthesis of this 
compound has been a matter of several debates questioning, that is, a pollutant with severe toxicity effects in human health. This review gives a global overview about the occurrence of DEHP naturally or synthetically.

\section{Di-2-ethylhexylphtalate (DEHP) Chemical Compound}

In general, phthalates are esters of phthalic acid, also known as esters of benzene-1,2-dicarboxylic acid. Phthalates contain a benzene ring with two ester groups. Their solubility in water decreases with an increase in the length of the carbon chain or molecular weight. Phthalates are oily liquids characterized by high boiling temperature, weak solubility in water, and satisfactory solubility in most organic solvents. These compounds are produced due to an esterification reaction to phthalic acid with various alcohols. Particularly, DEHP, also known as dioctyl phthalate (DOP), is obtained by the esterification reaction of 2-ethylhexanol with phthalic anhydride. It is a colorless liquid, and its molecular formula is $\mathrm{C}_{24} \mathrm{H}_{38} \mathrm{O}_{4}$ with a molecular weight of $390.57 \mathrm{~g} \cdot \mathrm{mol}^{-1}$. The compound is an isomeric substance due to the presence of diastereotopic protons adjacent to the chiral center. It has been widely used as plasticizer in many articles made of polyvinyl chloride (PVC) such as sewage pipe due to its low cost and chemical resistance [3, 13]. It has been also used to improve the plasticity and the flexibility of materials such as food packages, building, toys, and medical devices such as blood storage bags, intravenous fluid bags, and other products. It is present in many plastics, especially vinyl materials, which may contain up to $40 \%$ DEHP, although lower levels are common [14]. For example, DEHP has been used in PVC gloves that are used for cooking purposes. Several studies demonstrated the occurrence of phthalate in prepared lunches was mainly caused by DEHP containing PVC gloves used during the preparation of the foods [1316]. DEHP also finds use as a solvent in glowsticks. As the phthalate plasticizers are not chemically bound to PVC, they can leach, migrate, or evaporate into indoor air and atmosphere, foodstuff, other materials, etc. Therefore, the extended use of DEHP is more than obvious $[13,14]$.

Industrial production has been carried out following the reaction of phthalic anhydride $\mathbf{1}$ with 2-ethylhexanol $\mathbf{2}$. Esterification of phthalic anhydride by alcohol takes place in two stages. The first stage is so rapid that it can be carried out in the absence of catalyst. However, esterification of the second carboxylic group is very slow and needs to be facilitated by acid catalyst, and the resulting water must be removed from the reaction mixture to achieve di-2ethylhexylphtalate (DEHP) 3, as shown in Scheme 1.

The synthesis is very simple; however, there have been some studies about what catalyst is the most convenient and appropriate to give the best yields. Sulfuric acid, methanesulfonic acid, $p$-Toluenesulfonic acid, and sodium hydrogen sulfate are the most conventional homogeneous used catalysts. Among them, sulfuric acid, as a strong acid, has been one of the most employed, both in laboratory and industrial practice. However, the generation of some byproducts has leaded to replace it by $p$-toluenesulfonic acid that is less active catalyst but less aggressive. The applications of these catalysts cause some problems such as corrosion, loss of catalyst, and environment problems. Therefore, development of more efficient catalysts will be interesting and useful. A comparison is reported [17] between the homogeneous catalyst, $p$-toluenesulfonic acid, with heterogeneous catalysts such as zeolites and sulfated zirconia, demonstrating that heterogeneous catalysts showed high efficiency for esterification reactions. Another work, to study the kinetic model of this synthesis, uses methanesulfonic acid as a catalyst over the same reaction giving good results [18]. Each catalyst has some advantages over the others. It can be seemed that the heterologous catalysts showed high reaction yield, and they were used solvent free without requiring neutralization and washing steps, being of low cost and environmentally friendly catalysts.

The above-described method is the only way to synthesize DEHP; however, there are some studies on the optimization of synthesis of two starting materials that are used in the DEHP synthesis. There are two main routes to produce phthalic anhydride: the oxidation of $o$-xylene with air or $\mathrm{K}_{2} \mathrm{SO}_{4}$ as a promoter and oxidation of naphthalene in the same way using in both cases different silica gel and titania-supported catalysts, being $\mathrm{V}_{2} \mathrm{O}_{5} / \mathrm{TiO}_{2}$ catalyst which gives the best yields [19]. More recently, the oxidation of naphthalene was carried out with ozone to achieve phthalic anhydride; however, the yields were lower than before-used methods [20]. On the other side, 2-ethylhexanol is industrially produced through three consecutive reaction processes such as, propylene hydroformylation to $n$-butyraldehyde, $n$-butyraldehyde self-condensation, and typical aldol condensation reaction, which can be catalyzed by an acid, a base, or an acid-base bifunctional catalyst, to give 2ethyl-2-hexenal, and a hydrogenation, catalyzed by the supported $\mathrm{Cu}$ or Ni catalysts, of this last compound to give 2ethylhexanol [21]. More recently, the one-step synthesis of 2ethylhexanol from $n$-butyraldehyde was exploited using $\mathrm{Cu} / \mathrm{Mg}_{2.5} \mathrm{AlOx}$ catalyst. This one-step synthesis of $2 \mathrm{EHO}$ could simplify the process, reduce equipment costs and operating costs, and improve the process economy. However, this methodology is under investigation [22].

\section{Occurrence of DEHP in the Environment and Its Effects}

Phthalate esters are gradually released from industrial products during manufacturing, storage, use, and disposal [23]. The photodegradation and hydrolyzation rates of these pollutants are very slow under natural conditions. For example, DEHP has a half-life of 2000 years [24]. DEHP is used as an excipient in approved pharmaceutical formulations, added into polyvinyl chloride (PVC) to reinforce its flexibility, and to be used as a solvent for dyes. In general, DEHP is considered as high-volume selling plasticizer which could migrate to the environment and penetrate the human body through water, air, food, and medical equipment. It has been detected in many environmental places such as rivers, lakes, groundwater and wastewater, soil, sludge, and sediments. Phthalate esters can be released into the atmosphere as 


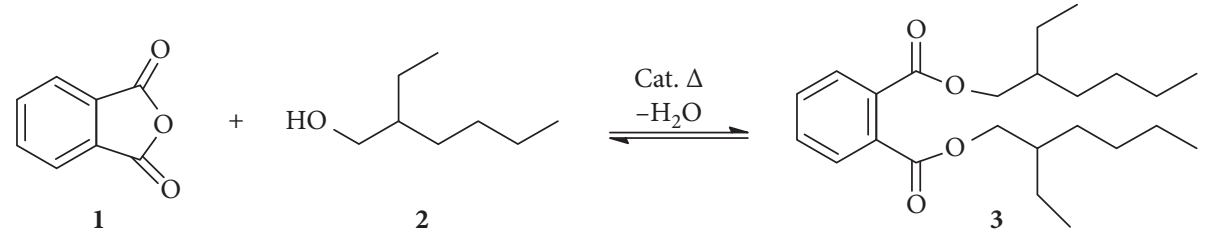

SCHEME 1: Synthesis of DEHP.

gaseous molecules, being temperature an important factor to control phthalate esters behavior. Despite the major phthalate esters are primarily present in vapor phase, DEHP preferred the particle phase. Rainfall transfers phthalate esters from the atmosphere to fresh water on land, causing their wide distribution in rivers, lakes, and sediments due to the natural hydrological cycle. DEHP is the predominant congener in both fresh water and sediments because of urbanization and industrialization. DEHP has low-water solubility; therefore, this compound concentrates from water into soil and sediments. There are many reports indicating the presence of diverse phthalates in agricultural soils being absorbed by crops and vegetables $[25,26]$. Due to the plastics used in agriculture, many of phthalates were found in arable soils [25]. The phthalate esters that accumulate in agricultural soils may be absorbed by crops and vegetables, causing direct damage to the human food chain. However, as it can be seen later, DEHP is related with microorganisms since some of them can produce this compound.

Due to the high concentration of this compound in diverse environments, there have been realized some studies about the effect of this compound on the human health. The environmental risk limit (ERL) for DEHP phthalates in soil is $1000 \mu \mathrm{g} / \mathrm{kg}$ fresh weight [27]. Due to their potential health and environmental risks, the World Health Organization (WHO), US, Australia, Japan, and New Zealand have recommended the concentration of DEHP in drinking water to be below $8,6,9,100$, and $10 \mu \mathrm{g} / \mathrm{L}$, respectively [28]. However, its potential toxicity is inconclusive. Some studies highlight its probable carcinogenic effect and its role as emerging endocrine disruptor and epigenetic toxicant. However, its potential toxicity is inconclusive. This compound is not severely toxic over a reasonable period; however, oxidized products of DEHP are probably more harmful than DEHP itself, because for humans the metabolism of DEHP seems to be more complex and involves several oxidative metabolites. Logically, many studies have been done in animals since they are more available for clinical trials; however, only few data are available for human toxicity being sometimes contradictory. There is no clear evidence about the association between exposure to DEHP and liver cancer in humans [29]. There are some studies [30] that have demonstrated that the exposure of a man to DEHP produce sperm abnormalities, such as reduced sperm count and motility, among others. Many other experiments about the effect of DEHP on human reproductive system have failed trying to detect the real adverse impact of DEHP in humans [31, 32]. About the effect of DEHP on several biological functions, there are many experiments that conclude that DEHP induces chromosomal aberrations, such as DNA strand breaks and gaps.

Consequently, there is a need to develop efficient processes to remove DEHP from different environments or degrade this compound. There are some questions about conventional treatment processes to degrade DEHP. One question is about if the physicochemical treatments are better than biological treatments. Normally, advanced oxidation processes have been developed and applied to remove DEHP at laboratory scale; however, for large-scale application, more research is need. This can be overcome by coupling this method with biological processes improving the DEHP biodegradation and reducing the operating cost as well as a shortening retention time [33]. It is important to consider the biodegradation pathway of DEHP that is shown in Figure 1. In Figure 1 are shown the different pathways that can follow DEHP biodegradation. It can be observed that the pathways are different using aerobic bacteria or anaerobic bacteria. Accordingly, bacteria can follow different ways through ortho- or metacleavage pathway [6]. There are many aerobic bacteria that can degrade phthalates primarily Arthrobacter sp., Pseudomonas sp., Sphingomonas sp., Burkholderia sp., Ochrobactrum sp., Serratia sp., Bacillus sp., and Acinetobacter sp. In addition to bacteria, some fungal species such as Aspergillus, sp., Fusarium sp., and Penicillium sp. can also degrade phthalates. Monoester phthalate and phthalic acid are common central intermediates in the anaerobic mineralization of phthalate esters. Phthalic acid should be converted to benzoate through decarboxylation, but no experimental evidence is available regarding the exact location of decarboxylation in degradation pathway. Benzoate degradation proceeds through ring cleavage to carbon dioxide, hydrogen, and acetate, which is converted into methane in further steps. The bacterial aerobic degradation of phthalate esters involves a sequence of reactions and is common to most microbes. As is shown in Figure 1, the cleavage of esters linkages is the common first step yielding phthalic acid. This acid can follow different routes depending if the bacteria is Gram positive or Gram negative. However, both routes converge in protocatechuate, which can follow different ways through ortho- or metacleavage pathway [34].

\section{Natural Product Isolated from Several Organisms and Its Activity}

Today, one of the biggest problems in the world related with the human health is that the number of drug-resistant bacteria has alarmingly increased; therefore, the search for new drugs has emerged as an interesting research area. In 


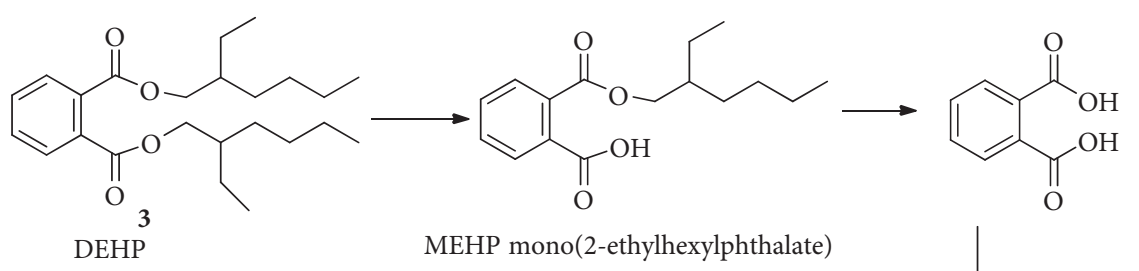

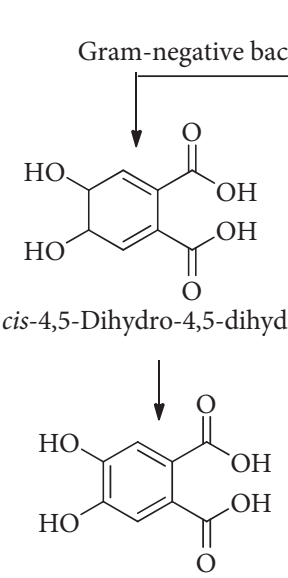

4,5-Dihydroxyphthalate

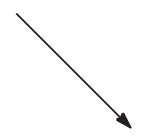<smiles>O=C(O)c1ccc(O)c(O)c1</smiles>

Protocatechuate Aerobic Gram-positive bacteria<smiles>O=C(O)c1ccc(O)c(O)c1C(=O)O</smiles>
3,4-Dihydroxyphthalate
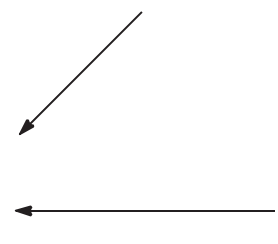

4-Hydroxybenzoate

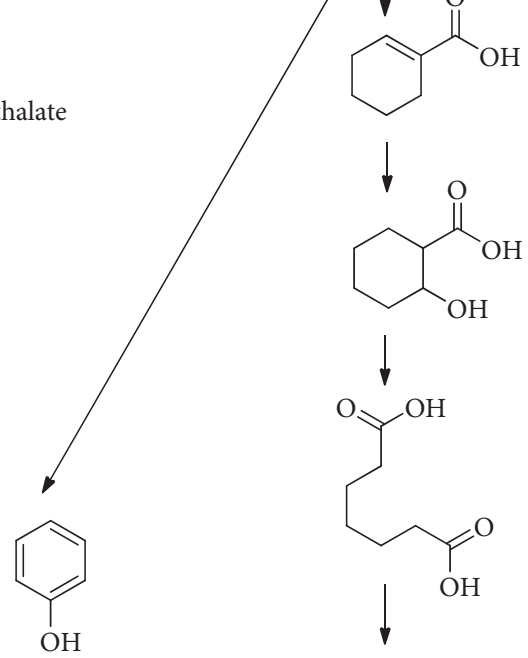

Acetate, $\mathrm{H}_{2}, \mathrm{CO}_{2}$<smiles>CC(CO)CC(=O)CCC(=O)O</smiles>

Meta cleavage<smiles>O=C(O)C1=C[C@H](O)[C@H](O)OC1=O</smiles>

4-Carboxy-2-hydroxymuconic semialdehyde<smiles>C/C=C(\C=C(/O)C(=O)O)C(=O)O</smiles>

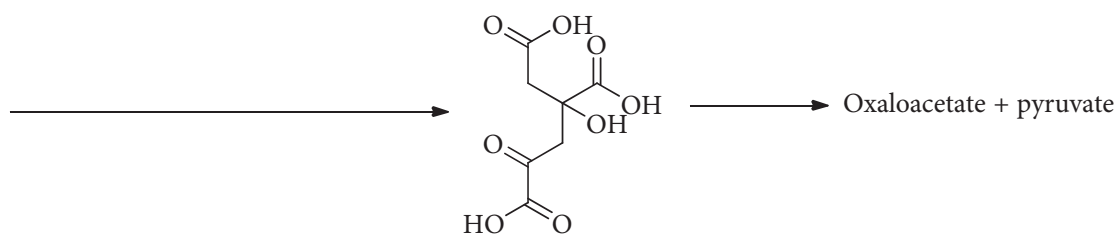

2-Hydroxy-4-carboxymuconic semialdehyde hemiacetal

FIgURE 1: Biodegradation pathway of DEHP.

this sense, microbial secondary metabolites have been the target for this search, since many of the most consumed antibiotics have been isolated from bacteria or fungi. Some of the chemical compounds isolated from microorganisms have other uses such as di-2-ethylhexylphtalate which has been widely used in plastics. As it has been mentioned, this compound has been considered as an environmental polluting due to the industrial origin. However, this idea has changed gradually since it has been found that this compound is synthesized by many organisms such as plants, bacteria, or fungi, and several studies have demonstrated different biological activities for this compound.

A phytochemical study on the flower of Calotropis gigantea showed the isolation of di-2-ethylhexyl phthalate [35]. In the same study, this compound showed an antibacterial and antifungal activity against Staphylococcus 
aureus, Bacillus subtilis, Sarcina lutea, Escherchia coli, Shigella sonnei, and Shigella shiga and Shigella dysenteriae bacteria and Aspergillus flavus fungus [35]. The same group more recently explored the anticancer activity of this compound showing that it has dose-dependent antitumor activity against Ehrlich ascites carcinoma cells in vivo [36].

As it has been mentioned, some microorganisms have also produced this compound. Among them, actinomycetes, also called filamentous bacteria, is a group that produces this compound. Streptomyces sp. produced di-2-ethylhexyl phthalate which showed antibacterial activities against Gram-positive bacteria and fungi [37]. From Streptomyces mirabilis has also been isolated the same compound with antimicrobial activities mainly against Gram-positive bacteria and yeasts [38]. An actinomycete identified as Nocardia levis produced this phthalate that showed a moderate antimicrobial activity against some Gram-positive bacteria and some fungi [39]. There is no much literature reporting the production of this compound by other genera of bacteria. The only report is about Bacillus cereus bacteria symbiotically associated with an entomopathogenic nematode sp., namely, Rhabditis (Oscheius) sp. which secreted DEHP to the culture showing high-antimicrobial activity [40]. The fungi are the largest microbial group secreting this compound. Penicillium species produce a very diversified array of active secondary metabolites, including antibacterial, antifungal, immunosuppressant, and cholesterol-lowering agents. Recently, it has been reported that Penicillium janthinellum produced DEHP as a major bioactive compound, showing in this report a potent dose-dependent antitumor activity against Ehrlich cells in vivo [41]. Another fungus that produces DEHP is Aspergillus fumigatus which was shown to secrete this compound [42]. Very recently, the same compound was isolated from Aspergillus awamori showing activity against Candida albicans fungus and against Gram-positive bacteria Sarcina lutea, having at the same time, cytotoxic activity against some carcinoma cell lines [43].

\section{Conclusions}

Di-2-ethylhexylphtalate is used as plasticizer during industrial production of PVC, paints, adhesives, cosmetics, and food packaging, among others [15]. These compounds easily migrate to the environment; therefore, they are present in any environment such as plants, soils, water, and sediments [26]. This situation can create a human health problem because of the high exposing levels for humans. In this sense, there have been many studies about the human health problems associated with the exposure to this kind of compounds, probing that they can cause infertility and reproductive problems in males [27]. To solve this problem, many researchers have tried to remove these pollutants from the environment. Many study results indicate that biodegradation under aerobic conditions is the best option for the mineralization of phthalate esters in the environment. The use of microorganisms for this purpose has been extensively reported [6]. However, it has been found that DEHP compound is synthesized by many organisms such as plants, bacteria, or fungi, and several studies have demonstrated different biological activities for this compound [38]. These data show that many microorganisms produce di-2ethylhexylphtalate but it is unclear if this compound is originated from secondary metabolisms of the living organisms or is absorbed from the accumulation of high levels of this compound from air and water. There is only one study with di-n-butyl phthalate (DBP) that demonstrates biosource production of this compound by filamentous fungi confirming that the fungal generation of DBP was largely through shikimic acid pathway, which was assembled by phthalic acid with butyl alcohol through esterification [44]. This study is very important because it confirmed the metabolic ability for biosynthesis of DBP. Until today, no studies have been done about other phthalates such as DEHP but it is very likely that the behavior is very similar, and the microorganisms can produce this compound through any of metabolic pathway. Therefore, this arises in the big question, is di-2-ethylhexylphthalate a natural product, rather than a pollutant? More research is needed to answer this question.

\section{Conflicts of Interest}

The authors declare that there are no conflicts of interest regarding the publication of this paper.

\section{Acknowledgments}

We thank VIEP (100518932 VIEP2018) and CONACYT (251512) for financial support.

\section{References}

[1] M. M. A. Daiem, J. Rivera-Utrilla, R. Ocampo-Perez, J. D. Mendez-Diaz, and M. Sanchez-Polo, "Environmental impact of phthalic acid esters and their removal from water and sediments by different technologies-a review," Journal of Environmental Management, vol. 109, pp. 164-178, 2012.

[2] D.-W. Gao and Z.-D. Wen, "Phthalate esters in the environment: a critical review of their occurrence, biodegradation, and removal during wastewater treatment processes," Science of the Total Environment, vol. 541, pp. 986-1001, 2016.

[3] S. Magdouli, R. Daghrir, S. K. Brar, P. Drogui, and R. D. Tyagi, "Di 2-ethylhexylphtalate in the aquatic and terrestrial environment: a critical review," Journal of Enviromental Management, vol. 127, pp. 36-49, 2013.

[4] S. Net, R. Sempere, A. Delmont, A. Paluselli, and B. Ouddane, "Occurrence, fate, behaviour and ecotoxicological state of phthalates in different environmental matrices," Environmental Science and Technology, vol. 49, no. 7, pp. 4019-4035, 2015.

[5] M. A. Park, K. A. Hwang, H. R. Lee, B. R. Yi, E. B. Jeung, and K. C. Choi, "Cell growth of BG-1 ovarian cancer cells is promoted by di-n-butyl phthalate and hexabromocyclododecane via upregulation of the cyclin D and cyclin-dependent kinase-4 genes," Molecular Medicine Reports, vol. 5, no. 3, pp. 761-766, 2012.

[6] D.-W. Liang, T. Zhang, H. H. P. Fang, and J. He, "Phthalates biodegradation in the environment," Applied and environmental biotechnology, vol. 80, no. 2, pp. 183-198, 2008.

[7] Y. Wang, B. Miao, D. Hou, X. Wu, and B. Peng, "Biodegradation of di-n-butyl phthalate and expression of the 3,4- 
phthalate dioxygenase gene in Arthrobacter sp. ZH2 strain," Process biochemistry, vol. 47, no. 6, pp. 936-940, 2012.

[8] J. Wang, M.-Y. Zhang, T. Chen et al., "Isolation and identification of a di-(2-ethylhexyl) phthalate-degrading bacterium and its role in the bioremediation of a contaminated soil," Pedosphere, vol. 25, no. 2, pp. 202-211, 2015.

[9] H.-M. Zhao, H. Du, J. Lin et al., "Complete degradation of the endocrine disruptor di-(2-ethylhexyl) phthalate by a novel Agromyces sp. MT-O strain and its application to bioremediation of contaminated soil," Science of the total Environment, vol. 562, pp. 170-178, 2016.

[10] J. Xu, Q. Lu, R. Alves de Toledo, and H. Shim, "Degradation of di-2-ethylhexyl phthalate (DEHP) by an indigenous isolate Acinetobacter sp. SN13," International Biodeterioration and Biodegradation, vol. 117, pp. 205-214, 2017.

[11] M. Ahuactzin-Perez, J. L. Torres, B. R. Rodriguez-Pastrana et al., "Fungal biodegradation of dibutyl phthalate and toxicity of its breakdown products on the basis of fungal and bacterial growth," World Journal of Microbiology and Biotechnology, vol. 30, no. 11, pp. 2811-2819, 2014.

[12] S. Pradeep and S. Benjamin, "Mycelial fungi completely remediate di (2-ethylhexyl)phthalate, the hazardous plasticizer in PVC blood storage bag," Journal of Hazardous Materials, vol. 235-236, pp. 69-77, 2012.

[13] P. A. Przybylinska and M. Wyszkowski, "Environmental contamination with phthalates and its impact on living organisms," Ecological Chemistry and Engineering S, vol. 23, no. 2, pp. 347-356, 2016.

[14] U. Heudorf, V. Mersch-Sundermann, and J. Angerer, "Phthalates: Toxicology and exposure," International journal of hygiene and environmental health, vol. 210, no. 5, pp. 623-634, 2007.

[15] T. Fierens, K. Servaes, M. Van Holderbeke et al., "Analysis of phthalates in food products and packaging materials sold on the Belgian market," Food and Chemical Toxicology, vol. 50, no. 7, pp. 2575-2583, 2012.

[16] Y. Tsumura, S. Ishimitsu, A. Kaihara, K. Yoshii, Y. Nakamura, and Y. Tonogai, "Di (2-ethylhexyl) phthalate contamination of retail packed lunches caused by PVC gloves used in the preparation of foods," Food Additives and Contaminants, vol. 18, no. 6, pp. 569-579, 2001.

[17] F. T. Sejidov, Y. mansoori, and N. Goodarzi, "Esterification reaction using solid heterogeneous acid catalysts under solvent-less condition," Journal of Molecular Catalysis A: Chemical, vol. 240, no. 1-2, pp. 186-190, 2005.

[18] J. Skrzypek, M. Lachowska, M. Kulawska, and H. Moroz, "Synthesis of bis(2-ethylhexyl) phthalate over methane sulfonic acid catalyst kinetic investigations," Reaction Kinetics and Catalysis Letters, vol. 93, no. 2, pp. 281-286, 2008.

[19] C. R. Dias, M. F. Portela, and G. C. Bond, "Synthesis of phthalic anhydride: catalysts, kinetics, and reaction modeling," Catalysis Reviews, vol. 39, no. 3, pp. 169-207, 1997.

[20] B. Rindone, F. Saliu, and R. Suarez-Bertoa, "The synthesis of phthalic anhydride via ozonation of naphthalene," Ozone: Science and Engineering, vol. 32, no. 3, pp. 161-165, 2010.

[21] C. Kohlpaintner, M. Schulte, J. Falbe, P. Lappe, and J. Weber, "Aldehydes, Aliphatic," in Ullmann's Encyclopedia of Industrial Chemistry, Wiley-VCH, Weinheim, Germany, 2008.

[22] S. Miao, H. An, X. Zhao, and Y. Wang, "Catalytic performance of $\mathrm{Cu}-\mathrm{Mg}-\mathrm{Al}$ in the one-step synthesis of 2-ethylhexanol from $n$-butyraldehyde," Reaction Kinetics, Mechanisms and Catalysis, 2018, In press.

[23] P. A. Clausen, Z. Liu, V. Kofoed-Sorensen, J. Little, and P. Wolkoff, "Influence of temperature on the emission of di- (2-ethylhexyl)phthalate (DEHP) from PVC flooring in the emission cell FLEC," Environmental Science \& Technology, vol. 46, no. 2, pp. 909-915, 2012.

[24] C. A. Staples, D. R. Peterson, T. F. Parkerton, and W. J. Adams, "The environmental fate of phthalate esters: a literature review," Chemosphere, vol. 35, no. 4, pp. 667-749, 1997.

[25] X. Y. Hu, B. Wen, and X. Q. Shan, "Survey of phthalate pollution in arable soils in China," Journal of Environmental Monitoring, vol. 5, no. 4, pp. 649-653, 2003.

[26] T. T. Ma, P. Christie, Y. M. Luo, and Y. Teng, "Phthalate esters contamination in soil and plants on agricultural land near an electronic waste recycling site," Environmental Geochemistry and Health, vol. 35, no. 4, pp. 465-476, 2013.

[27] A. P. Van Wezel, P. Van Vlaardingen, R. Posthumus, G. H. Crommentuijn, and D. T. H. M. Sijm, "Environmental risk limits for two phthalates, with special emphasis on endocrine disruptive properties," Ecotoxicology and Environmental Safety, vol. 46, no. 3, pp. 305-321, 2000.

[28] WHO, Guidelines for Drinking Water Quality, WHO, Geneva, Switzerland, 3rd edition, 2004.

[29] I. Rusyn and J. C. Corton, "Mechanistic considerations for human relevance of cancer hazard of di(2-ethylhexyl) phthalate," Mutation Research, vol. 750, no. 2, pp. 141-158, 2011.

[30] G. Pan, T. Hanaoka, M. Yoshimura et al., "Decreased serum free testosterone in workers exposed to high levels of di- $n$ butyl phthalate (DBP) and di- 2-ethylhexyl phthalate (DEHP): a cross-sectional study in China," Environmental Health Perspectives, vol. 114, no. 11, pp. 1643-1648, 2006.

[31] R. Lambrot, V. Muczynski, C. Lecureuil et al., "Phthalates impair germ cell development in the human fetal testis in vitro without change in testosterone production," Environmental Health Perspectives, vol. 117, no. 1, pp. 32-37, 2009.

[32] B. A. Jonsson, J. Richthoff, L. Rylander, A. Giwercman, and L. Hagmar, "Urinary phthalate metabolites and biomarkers of reproductive function in young men," Epidemiology, vol. 16, no. 4, pp. 487-493, 2005.

[33] T. T. H. Pham, R. D. Tyagi, S. K. Brar, and R. Y. Surampalli, "Effect of ultrasonication and Fenton oxidation on biodegradation of bis(2-ethylhexyl) phthalate (DEHP) in wastewater sludge," Chemosphere, vol. 82, no. 6, pp. 923-928, 2011.

[34] D.-W. Gao and Z.-D. Wen, "Phthalate esters in the environment: a critical reviewof their occurrence, biodegradation, and removal during wastewater treatment processes," Science of the Total Environment, vol. 541, pp. 986-1001, 2016.

[35] M. R. Habib and M. R. Karim, "Antimicrobial and cytotoxic activity of di-(2-ethylhexyl) phthalate and anhydrosophoradiol-3-acetate isolated from Calotropis gigantea (Linn.) Flower," Mycobiology, vol. 37, no. 1, pp. 31-36, 2009.

[36] M. R. Habib and M. R. Karim, "Antitumour evaluation of di(2-ethylhexyl) phthalate (DEHP) isolated from Calotropis gigantea L. flower," Acta Pharmaceutica, vol. 62, no. 4, pp. 607-615, 2012.

[37] S. Smaoui, L. Mellouli, A. Lebrihi, Y. Coppel, L. F. B. Fguira, and F. Mathieu, "Purification and structure elucidation of three naturally bioactive molecules from the new terrestrial Streptomyces sp. TN17 strain," Natural Product Research, vol. 25, no. 8, pp. 806-814, 2011.

[38] M. H. El-Sayed, "Di-(2-ethylhexyl) phthalate, a major bioactive metabolite with antimicrobial and cytotoxic activity isolated from the culture filtrate of newly isolated soil 
streptomyces (Streptomyces mirabilis Strain NSQu-25)," World Applied Sciences Journal, vol. 20, pp. 1202-1212, 2012.

[39] A. Kavitha, P. Prabhakar, M. Vijayalakshmi, and Y. Venkateswarlu, "Production of bioactive metabolites by Nocardia levis MK-VL_113," Letters in Applied Microbiology, vol. 49, no. 4, pp. 484-490, 2009.

[40] K. M. Anju, M. M. Archana, C. Mohandas, and B. Nambisan, "An antimicrobial phthalate derivative from bacillus cereus, the symbiotic bacterium associated with a novel entomopathogenic nematode, Rhabditis (Oscheius) Sp.," International Journal of Pharmacy and Pharmaceutical Sciences, vol. 7, pp. 238-242, 2015.

[41] O. H. El-Sayed, M. M. S. Asker, S. M. Shash, and S. R. Hamed, "Isolation, structure elucidation and biological activity of di(2-ethylhexyl) phthalate produced by penicillium janthinellum 62," International Journal of ChemTech Research, vol. 8, pp. 58-66, 2015.

[42] M. S. Abdel-Aziz, M. A. Ghareeb, A. M. Saad, L. A. Refahy, and A. A. Hamed, "Chromatographic isolation and structural elucidation of secondary metabolites from the soil-inhabiting fungus aspergillus fumigatus 3T-EGY," Acta Chromatographica, 2017, In press.

[43] M. M. Lotfy, H. M. Hassan, M. H. Hetta, A. O. El-Gendy, and R. Mohammed, "Di-(2-ethylhexyl) Phthalate, a major bioactive metabolite with antimicrobial and cytotoxic activity isolated from River Nile derived fungus Aspergillus awamori," Beni-Suef University Journal of Basic and Applied Sciences, vol. 7, no. 3, pp. 263-269, 2018.

[44] C. Tian, J. Ni, F. Chang et al., "Bio-Source of di-n-butyl phthalate production by filamentous fungi," Scientific Reports, vol. 6, article 19791, 2016. 

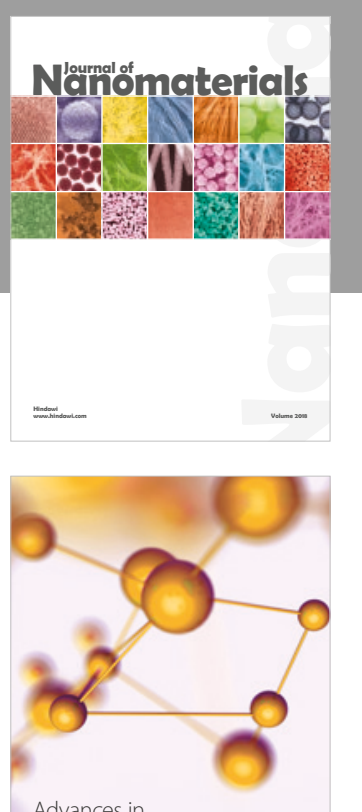

Physical Chemistry
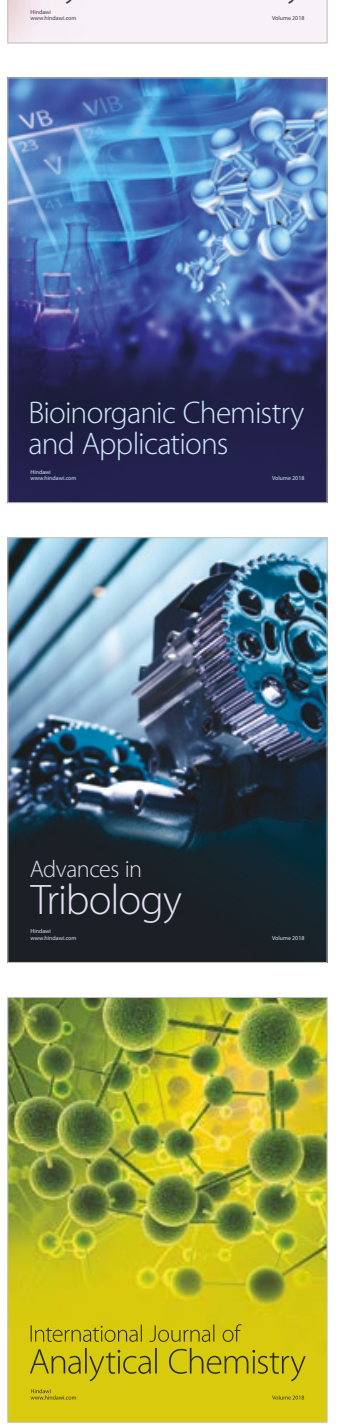

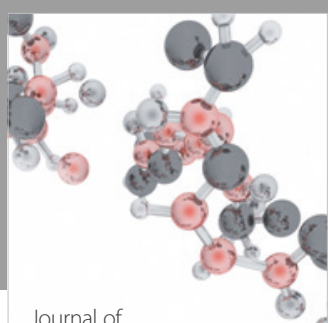

Analytical Methods

in Chemistry

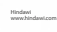

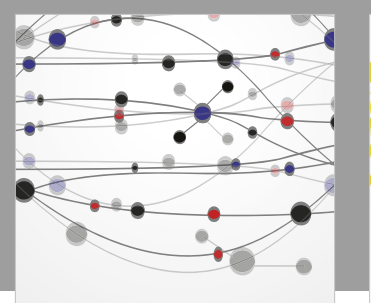

The Scientific World Journal

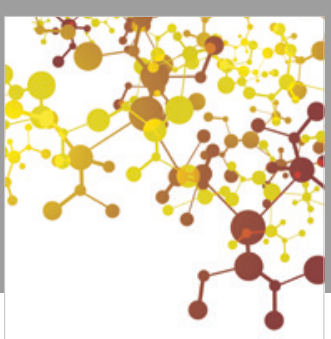

Journal of

Applied Chemistry
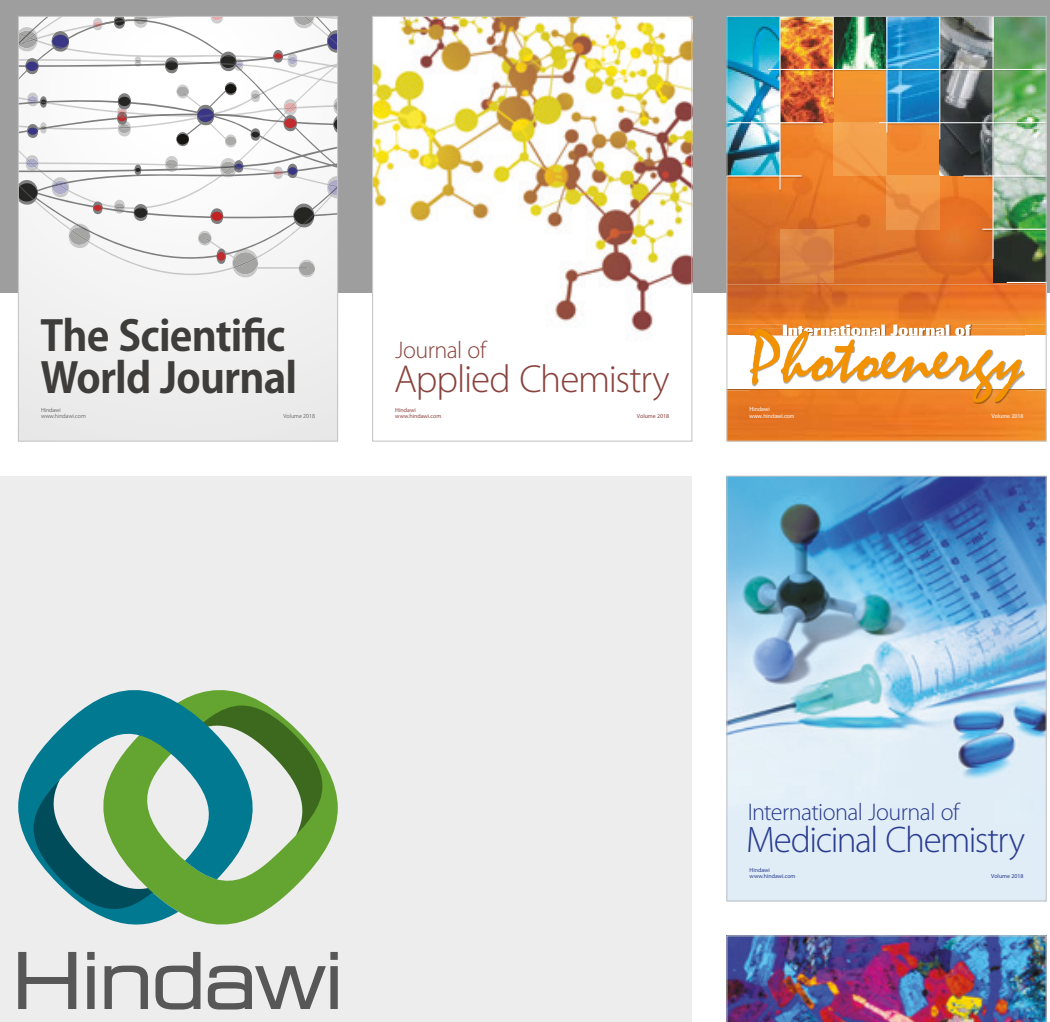

Submit your manuscripts at

www.hindawi.com
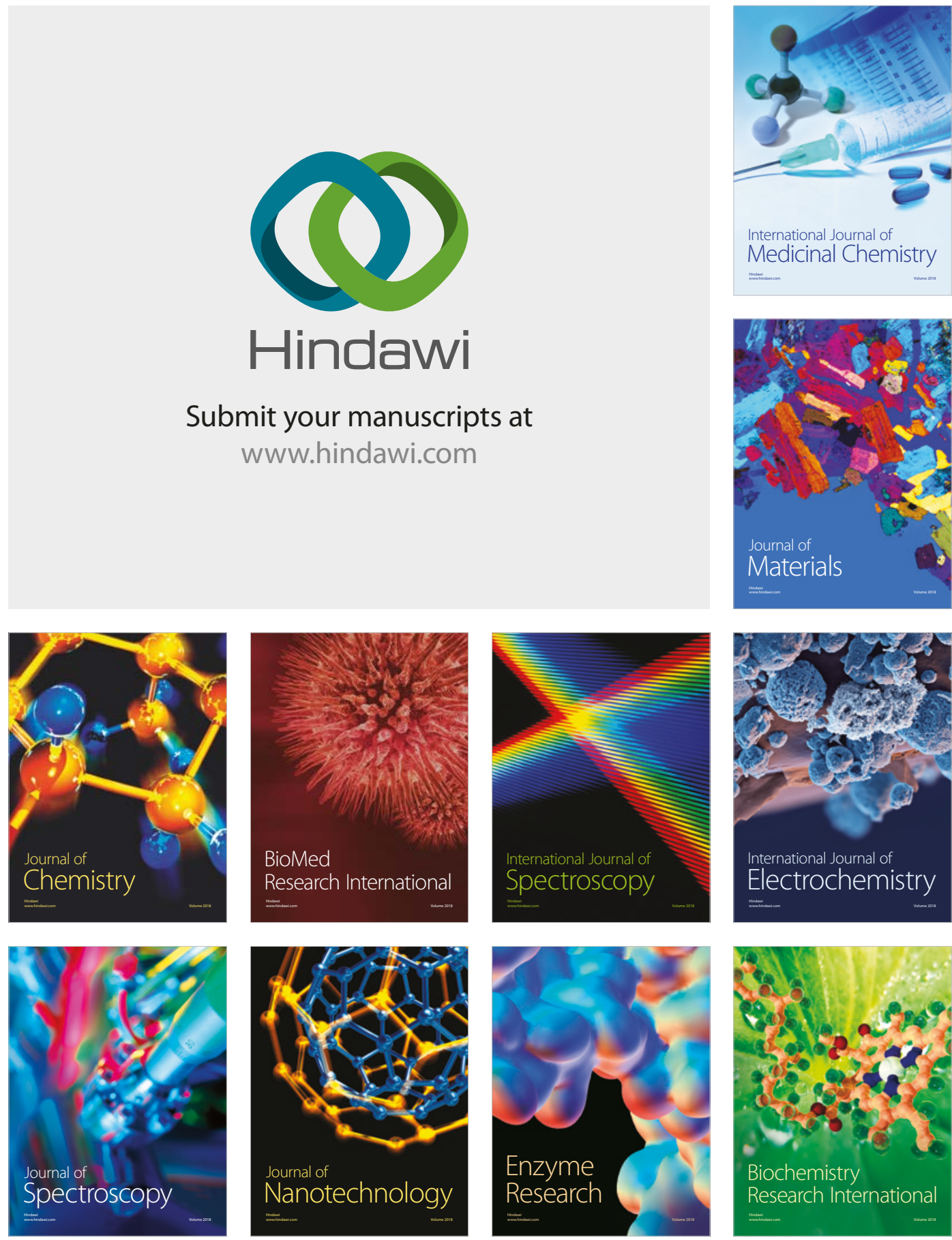
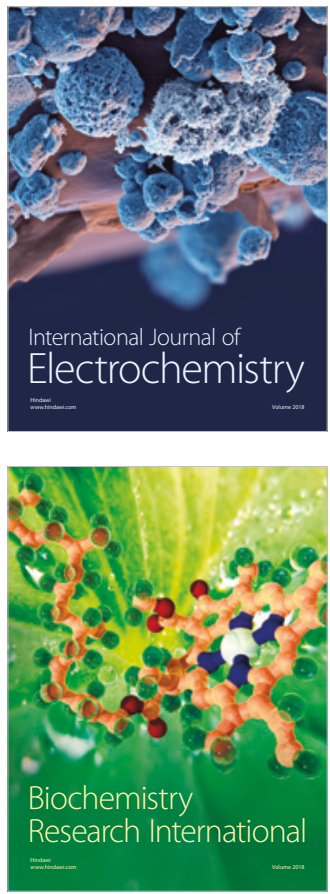